\title{
Observed and simulated precursors of stratospheric polar vortex anomalies in the Northern Hemisphere
}

\author{
Erik W. Kolstad • Andrew J. Charlton-Perez
}

Received: 3 February 2010/Accepted: 19 September 2010/Published online: 5 October 2010

(C) The Author(s) 2010. This article is published with open access at Springerlink.com

\begin{abstract}
The Northern Hemisphere stratospheric polar vortex is linked to surface weather. After Stratospheric Sudden Warmings in winter, the tropospheric circulation is often nudged towards the negative phase of the Northern Annular Mode (NAM) and the North Atlantic Oscillation (NAO). A strong stratospheric vortex is often associated with subsequent positive NAM/NAO conditions. For stratosphere-troposphere associations to be useful for forecasting purposes it is crucial that changes to the stratospheric vortex can be understood and predicted. Recent studies have proposed that there exist tropospheric precursors to anomalous vortex events in the stratosphere and that these precursors may be understood by considering the relationship between stationary wave patterns and regional variability. Another important factor is the extent to which the inherent variability of the stratosphere in an atmospheric model influences its ability to simulate stratosphere-troposphere links. Here we examine the lower stratosphere variability in 300-year pre-industrial control integrations from 13 coupled climate models. We show that robust precursors to stratospheric polar vortex anomalies are evident across the multi-model ensemble. The most significant tropospheric component of these precursors consists of a height anomaly dipole across northern Eurasia
\end{abstract}

E. W. Kolstad ( $\square)$

Bjerknes Centre for Climate Research,

Allégaten 55, 5007 Bergen, Norway

e-mail: erik.kolstad@uni.no

E. W. Kolstad

Uni Bjerknes Centre,

Bergen, Norway

A. J. Charlton-Perez

Department of Meteorology,

University of Reading, Reading, UK and large anomalies in upward stationary wave fluxes in the lower stratosphere over the continent. The strength of the stratospheric variability in the models was found to depend on the variability of the upward stationary wave fluxes and the amplitude of the stationary waves.

Keywords Stratosphere-troposphere interactions . Stratospheric variability $\cdot$ Stationary waves $\cdot$ Stratospheric sudden warmings $\cdot$ Northern annular mode . Climate models

\section{Introduction}

The strength and location of the Northern Hemisphere $(\mathrm{NH})$ stratospheric polar vortex are linked to circulation anomalies in the troposphere (Thompson et al. 2002; Scaife et al. 2005). Baldwin and Dunkerton $(1999,2001)$ showed that during the first 60 days after the onset of anomalous weak stratospheric vortex regimes, or stratospheric sudden warmings (SSWs), in winter, the large-scale tropospheric circulation is nudged towards the negative phase of the Northern Annular Mode (NAM) and the North Atlantic Oscillation (NAO). The NAM/NAO is the dominant weather pattern in the North Atlantic region, and negative anomalies during winter trigger near-surface cold anomalies in large regions of the NH (Thompson et al. 2002; Kolstad et al. 2010), such as during the winter of 2009-2010. Stronger-than-normal stratospheric vortex events are associated with subsequent positive NAM/NAO conditions (Ambaum and Hoskins 2002; Wittman et al. 2004; Scaife et al. 2005). In light of these stratospheretroposphere associations, the potential for tropospheric prediction based on the state of the stratospheric vortex has been studied extensively in recent years (Baldwin et al. 
2003; Charlton et al. 2003, 2004; Douville 2009; Stan and Straus 2009).

Whether or not these stratosphere-troposphere associations can be exploited for predictive purposes depends on how well changes to the stratospheric vortex can be understood and predicted in advance (Limpasuvan et al. 2004; Polvani and Waugh 2004; Orsolini et al. 2010). It is known that stratospheric vortex anomalies are preceded by positive poleward anomalies in the zonal-mean heat fluxes in the lower stratosphere (Polvani and Waugh 2004) and increased baroclinic wave energy associated with planetary-scale waves (Liberato et al. 2007; Castanheira et al. 2009). However, the relationship between anomalous tropospheric planetary wave amplitudes and subsequent stratospheric variability is complex and dependent on the state of the stratosphere-troposphere system at the time of the generation of planetary wave anomalies (Reichler et al. 2005).

A number of studies have linked anomalously high upward fluxes of wave energy into the stratosphere to variations in the Eurasian snow cover during the transition from autumn to winter. A series of papers from the late 1990s (Cohen and Entekhabi 1999; Cohen et al. 2001; Saito et al. 2001) introduced the idea that year-to-year variations in October Eurasian snow cover lead to variations in the structure and strength of the Siberian High, that these variations lead to changes in the wave activity flux entering the stratosphere during the winter season, and that these fluxes are responsible for significant variations in the strength of the stratospheric polar vortex (see discussion in Cohen et al. 2007). There has been some debate in the literature about the significance of these precursors (see Limpasuvan et al. 2004; Cohen et al. 2005; Limpasuvan et al. 2005b). Several recent studies, however, have shown both that Eurasian snow cover perturbations can be used to make successful predictions of wintertime temperatures (Cohen and Fletcher 2007) and that imposed snow cover anomalies are capable of generating significant stratospheric variability, albeit modulated by the prior state of the stratosphere (Fletcher et al. 2007, 2009).

Recently, Garfinkel et al. (2010) and Smith et al. (2010) have proposed a new framework for understanding the tropospheric precursors of stratospheric variability. Both studies suggest that tropospheric precursors to stratospheric variability could be understood by considering the linear interference between the background stationary wave pattern and the anomalous regional variability in the $\mathrm{NH}$. In addition to understanding the links between Eurasian snow cover and stratospheric variability linear interference, these ideas may also prove useful in understanding the recently studied links between variability in the tropical Pacific and European winter conditions via a stratospheric pathway (Bell et al. 2009; Cagnazzo and Manzini 2009; Ineson and Scaife 2009).

Another important factor in understanding the stratosphere-troposphere links is the extent to which the inherent variability of the stratosphere in an atmospheric model influences its ability to simulate these links (Gerber and Polvani 2009). Models differ greatly in their ability to reproduce observed stratospheric variability (Charlton et al. 2007; Maycock et al. 2010). This ability appears not to depend simply upon the models' upper lid height or stratospheric resolution.

One way of making progress on both of these issues is to examine the relationship between stratospheric variability and its tropospheric precursors in a large ensemble of different models. In this study, we adopt such an approach by examining the variability of the lower stratosphere in long pre-industrial control integrations, of a subset of the world climate research programme's (WCRP's) coupled model intercomparison project phase 3 (CMIP3) models (Meehl et al. 2007). The advantage of using such integrations is that the influence of externally forced climate variability (from volcanoes, aerosols or trends in greenhouse gas forcing) on the stratosphere and troposphere is eliminated. The large ensemble available to us (we used 300 years for each of the 13 models) also means that the detection of significant stratosphere-troposphere links is easier. It is of course important to state at the beginning of our study, however, that as in other studies, the diagnosis of physically meaningful relationships is dependent upon the level of realism of the models concerned.

Hardiman et al. (2008) used the CMIP3 models to examine the links between Eurasian snow cover and stratospheric variability. One important point to note from Hardiman et al. (2008) is that the CMIP3 models appear to exhibit a limited connection between Eurasian snow cover and wintertime temperature in the NH. Hardiman et al. (2008) link this weak connection primarily to the weak snow cover variability in the models. Here we wish to expand on that study in seeking to broadly characterise tropospheric precursors to strong and weak stratospheric vortex events. As in other model inter-comparison studies, the physical process of interest (here tropospheric precursors to anomalous stratospheric vortex events) will vary considerably between different models.

The two main purposes of this paper are: (1) To identify robust precursors of stratospheric variability events across the multi-model ensemble to enhance our understanding of the stratosphere-troposphere links, and (2) To compare the stratospheric variability across the multi-model ensemble to develop tentative hypotheses about the role of the troposphere in determining the stratospheric vortex variability.

\section{Data and methods}

Monthly mean data from the NCEP/NCAR re-analysis (NNR from now on) (Kalnay et al. 1996) in the period from 
Table 1 Names and sample statistics of the models and re-analysis

\begin{tabular}{|c|c|c|c|c|c|c|c|}
\hline Model id (abbreviation) & $\begin{array}{l}\text { Model } \\
\text { top }\end{array}$ & $\begin{array}{l}\text { Standard } \\
\text { deviation of } Z_{\mathrm{PC}} \\
\text { anomalies }(\mathrm{m})\end{array}$ & $\begin{array}{l}\text { Skewness } \\
\text { of } Z_{\mathrm{PC}} \\
\text { anomalies (m) }\end{array}$ & $\begin{array}{l}\text { Mean }\left[U_{\mathrm{g}}\right] \\
\text { at } 50 \mathrm{hPa} \text {, } \\
60^{\circ} \mathrm{N}\left(\mathrm{m} \mathrm{s}^{-1}\right)\end{array}$ & $\begin{array}{l}\text { Standard deviation } \\
\text { of }\left[U_{\mathrm{g}}\right] \text { at } 50 \mathrm{hPa} \text {, } \\
60^{\circ} \mathrm{N}\left(\mathrm{m} \mathrm{s}^{-1}\right)\end{array}$ & $\begin{array}{l}{\left[U_{\mathrm{g}}\right] \text { at } 50 \mathrm{hPa},} \\
60^{\circ} \mathrm{N} \text { during } \\
\mathrm{WVMs}\left(\mathrm{m} \mathrm{s}^{-1}\right)\end{array}$ & $\begin{array}{l}{\left[U_{\mathrm{g}}\right] \text { at } 50 \mathrm{hPa},} \\
60^{\circ} \mathrm{N} \text { during } \\
\mathrm{SVMs}\left(\mathrm{m} \mathrm{s}^{-1}\right)\end{array}$ \\
\hline NCEP/NCAR reanalysis (NNR) & High & 202 & 0.24 & 18.6 & 8.4 & 5.8 & 30.7 \\
\hline BCCR-BCM2.0 (BCM) & Low & 88 & 0.14 & 14.2 & 3.1 & 9.3 & 19.1 \\
\hline CCSM3 (CCSM) & Low & 185 & 0.81 & 27.1 & 7.2 & 14.6 & 36.2 \\
\hline CGCM3.1(T63) (CGCM) & High & 169 & 0.15 & 14.7 & 5.8 & 5.6 & 24.1 \\
\hline CNRM-CM3 (CNRM) & High & 140 & 0.02 & 14.4 & 5.5 & 5.8 & 22.1 \\
\hline ECHAM5/MPI-OM (ECHAM) & Low & 107 & 0.37 & 16.9 & 4.0 & 10.5 & 22.8 \\
\hline GISS-ER (GISS) & High & 97 & 0.31 & 18.5 & 3.5 & 12.7 & 23.8 \\
\hline GFDL-CM2.1 (GFDL) & Low & 149 & -0.05 & 19.7 & 6.5 & 10.8 & 29.3 \\
\hline IPSL-CM4 (IPSL) & Low & 139 & 1.00 & 27.0 & 5.5 & 18.8 & 34.8 \\
\hline INM-CM3.0 (INM) & Low & 166 & 0.02 & 15.7 & 5.7 & 6.6 & 25.5 \\
\hline MIROC3.2 (medres) (MIROC) & High & 89 & -0.04 & 12.7 & 3.5 & 8.1 & 18.1 \\
\hline MRI-CGCM2.3.2 (MRI) & High & 192 & 0.18 & 21.7 & 7.5 & 9.7 & 32.0 \\
\hline PCM & Low & 160 & 0.19 & 22.6 & 6.2 & 13.1 & 30.7 \\
\hline UKMO-HadCM3 (UKMO) & Low & 136 & -0.42 & 12.8 & 5.6 & 6.0 & 22.8 \\
\hline
\end{tabular}

The model abbreviations used in this paper are listed in parentheses in the first column. Following Cordero and Forster (2006), models with a model top lower (higher) than $45 \mathrm{~km}$ were classified as Low (High)

the winter of 1958-1959 to the winter of 2009-2010 were used. Our analysis was repeated in full with the ERA-40 data set (Uppala et al. 2005), but as the differences with respect to the NNR were considered to be negligible in the context of our study, we decided to present only the results obtained with the NNR. The CMIP3 models that were used are listed in Table 1, along with a selection of parameters that relate to the stratospheric polar vortex. We used results from a more recent version of BCM than the one used in CMIP3, as described by Otterå et al. (2009). A thorough investigation of the stratospheric variability of these models and others are found in Cordero and Forster (2006). All the models that provided 300 years or more of pre-industrial control runs were used, and we used 300-year time slices of each.

Many indices have been used to characterise vortex strength. The most direct index is the zonal wind speed at $60^{\circ} \mathrm{N}$, but Baldwin and Thompson (2009) have shown that the zonal-mean NAM indices or area-averaged polar cap geopotential anomalies are more effective when studying stratosphere-troposphere couplings. Here we compute monthly-mean, area-averaged 50 -hPa polar cap geopotential height anomalies as $Z_{\mathrm{PC}} \equiv \sum\left(Z^{\prime} \cos \varphi\right) / \sum \cos \varphi$, where $Z^{\prime}=Z-\bar{Z}, Z$ is the geopotential height, $\bar{Z}$ is its climatological mean and $\varphi$ is the latitude. The sum was performed on all grid points north of $65^{\circ} \mathrm{N}$. The $50-\mathrm{hPa}$ level was chosen because it was the highest level below $10 \mathrm{hPa}$ that was available for all the data sources. On the daily time scale, $Z_{\mathrm{PC}}$ corresponds closely to the zonal-mean NAM index (Baldwin and Thompson 2009).
To examine the structure of stratospheric variability in the re-analysis and the CMIP3 models, weak vortex months (WVMs) and strong vortex months (SVMs) are defined as the months for which $Z_{\mathrm{PC}}$ is greater than its wintertime (December-March: DJFM) 90th percentile or less than its wintertime 10th percentile, respectively. When two or more consecutive months satisfied this constraint, only the first of these was included.

As an index of stationary wave activity, we used a slightly rewritten version of the vertical component of the 'Plumb flux' vector defined in Eq. (7.1) by Plumb (1985):

$F_{\mathrm{z}}=\frac{2 \Omega p \cos \phi \sin \phi}{S}\left[v_{g}^{*} T^{*}-\frac{g}{2 \Omega a \sin 2 \phi} \frac{\partial}{\partial \lambda}\left(T^{*} Z^{*}\right)\right]$,

where geostrophic winds were used, as recommended by Karoly et al. (1989). The asterisks indicate anomalies from zonal means, $a$ is the Earth's radius, $\Omega$ its angular speed of rotation, $\phi$ is the latitude, $\lambda$ is the longitude, and $S$ is a measure of the NH static stability (defined by Eq. (7.2) in Plumb 1985). Note that we computed $F_{\mathrm{z}}$ for each month, and not for long-term mean fields, as was done by Plumb (1985).

\section{Stratospheric vortex variability}

Prior to examining precursor patterns for stratospheric vortex anomalies, it is first necessary to examine the variability in the different models. Time series of the seasonal (DJFM) and 15-year running means of the vortex strength 
index $Z_{\mathrm{PC}}$ for the NNR and the 13 models are shown in Fig. 1. The model years on the $x$-axes are arbitrary because the external forcing is constant in the pre-industrial control runs. These data cannot be compared year for year with the NNR data, which are shown for the period 1959-2010 (where the years given correspond to end of the winters). Note that the individual winter months were given equal weight when computing the seasonal means, both for simplicity and because some of the models have 360day years and 30-day months.

Amongst the model ensemble, there are considerable differences in several aspects of $Z_{\mathrm{PC}}$. The standard deviations of $Z_{\mathrm{PC}}$ on the monthly time scale and the zonally averaged long-term mean geostrophic zonal wind for each data source are listed in the third and sixth columns of Table 1, respectively. Several models have much lower monthly variability than the NNR (by more than a factor of two in BCM, ECHAM, GISS and MIROC). However, as there is a trend in the NNR data and as trends act to inflate variance, it is important to check if these discrepancies could be due to the differences in the length of the time series (52 years for the NNR and 300 years for the models). We therefore computed the standard deviations for all the possible 52-year periods in the model data. For each model, we then checked if the 0.975 quantile of these values was greater than the standard deviation of the NNR, but this happened only for CCSM and MRI.

For the models, there is no obvious correspondence between the model top and the amount of inter-annual variability in the stratosphere (for example GISS has a model top at $0.1 \mathrm{hPa}$ ). From Fig. 1 it is also apparent that a large amount of inter-decadal variability is present in some of the models. Multiple rigorous attribution studies have shown that recent stratospheric trends can be traced to a combined influence of greenhouse gas and stratospheric ozone changes (Randel et al. 2009), but Fig. 1 shows that even in unperturbed climate runs, secular trends in $Z_{\mathrm{PC}}$ similar to that observed in the re-analysis occur at several points in the integration of some of the models (for example near year 200 in the CCSM model integration).

The skewness of $Z_{\mathrm{PC}}$ in each data source is listed in the fourth column of Table 1. Right-skewed distributions, for which the skewness is positive, generally have a long right tail and their mean value to the right of the median. Rightskewed $Z_{\mathrm{PC}}$ distributions suggest that WVMs are less common but more extreme than SVMs. The skewness of $Z_{\mathrm{PC}}$ in the NNR is 0.24 . For the models, a wide range of skewness values are found, from -0.42 in UKMO (suggesting that SVMs dominate) to 1.00 in IPSL.

The models' abilities to simulate large deviations of vortex strength can also be assessed from the two rightmost columns of Table 1, where the zonal-mean geostrophic westerly winds at $50 \mathrm{hPa}$ and $60^{\circ} \mathrm{N}$, averaged during WVMs and SVMs, are shown. These numbers should be held against the average jet strength in the fifth column of Table 1. Only a few models are able to produce as weak winds during WVMs as the NNR, but for these models, both the average winds and the winds during SVMs are weaker than in the NNR.

In Fig. 2, the mean 50-hPa geopotential height anomalies during WVMs for each of the models are shown with coloured shadings. Large, positive anomalies are observed over the polar cap, with a similar structure and spatial scale in the models and the NNR. Although not shown here, the patterns during SVMs are similar in spatial structure, but with anomalies of opposite signs to the WVM patterns. The weighted climatological averages (meaning that the longterm average was weighted with respect to the seasonal distribution of the SVMs and WVMs) of $Z^{*}=Z-[Z]$, the geopotential height with its zonal mean removed, are shown with black contours to indicate the locations and amplitudes (the difference between the maxima and
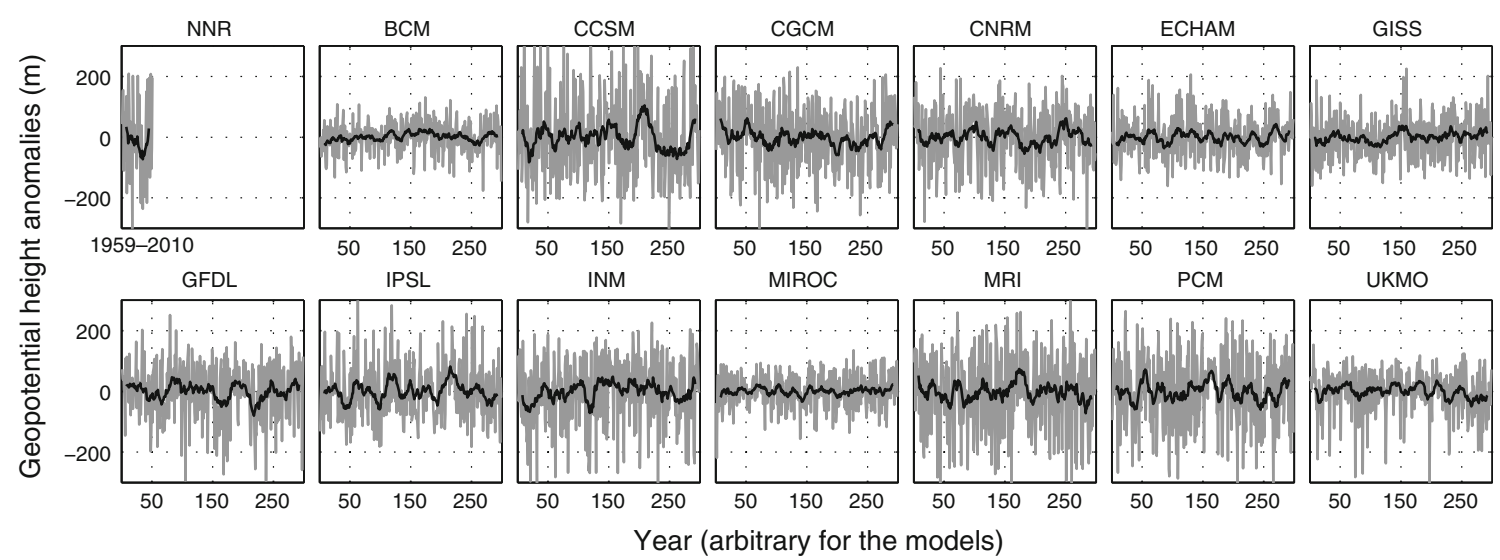

Fig. 1 Polar cap geopotential height $\left(Z_{\mathrm{PC}}\right)$ anomalies. Seasonal (DJFM) mean area-averaged $50-\mathrm{hPa}$ geopotential height anomalies north of $65^{\circ} \mathrm{N}$ are shown in gray and 15 -year running mean values are shown in black (with the first and last 7 years omitted). The years for the pre-industrial control runs are arbitrary and the NNR data are for the period 1959-2010 


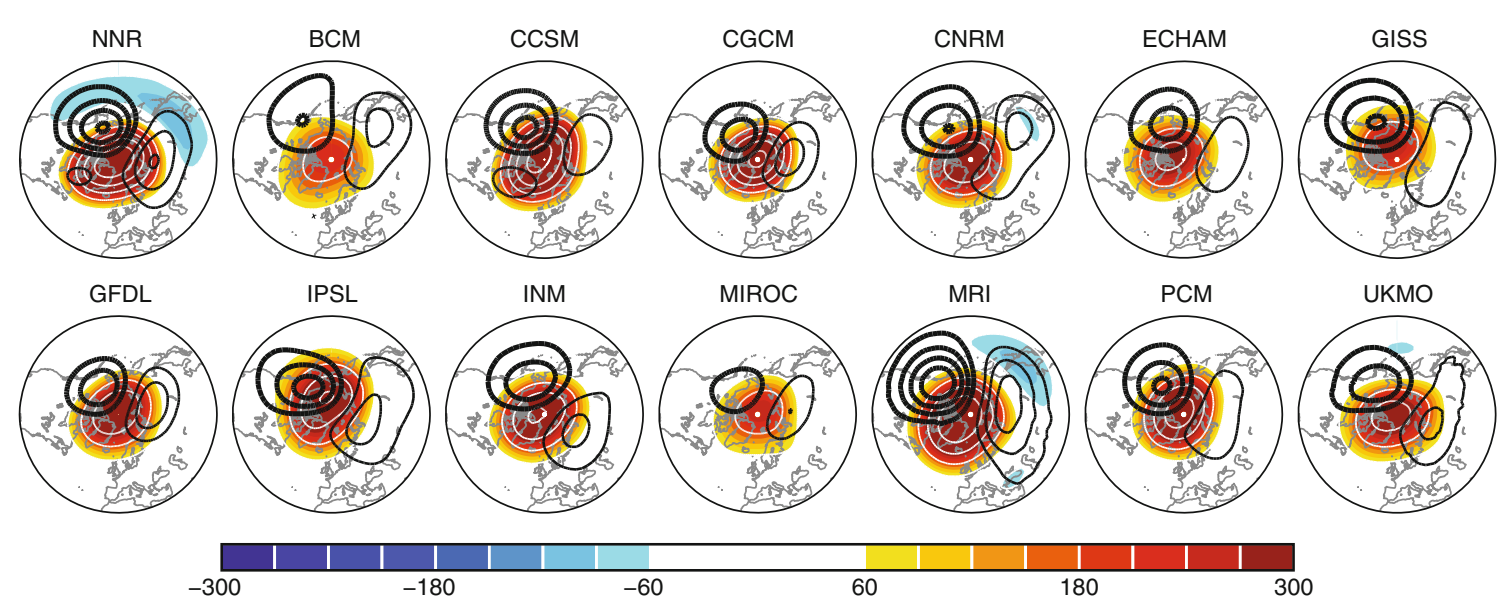

Fig. 2 Average 50-hPa geopotential height anomalies during WVMs are shown with filled contours (in metres). White contours are shown for each $120 \mathrm{~m}$, starting at $\pm 180 \mathrm{~m}$. Climatological mean anomalies

minima of $Z^{*}$ in Fig. 2) of the large-scale stationary waves. The models agree well in determining the spatial stationary wave structure in the stratosphere, with a strong focus toward a wave-number one ridge-trough pattern across the Bering Strait region, albeit with different amplitudes. We note that models with low stratospheric vortex variability tend to have weak stationary wave amplitude, a relationship that we pursue further in Sect. 5, where inter-model differences are examined.

\section{Precursors of vortex anomalies}

In this section simulated and observed standardised anomalies during the months prior to both WVMs and SVMs are analysed. By standardised we mean that the anomalies were divided by their month-wise long-term standard deviation. This was done to assign equal weights to all the models, as their stratospheric polar vortex variance differs substantially (cf. Fig. 1; Table 1).

\subsection{Weak vortex months}

In Fig. 3 the average standardised geopotential height anomalies at 700 and $100 \mathrm{hPa}$ one month before WVMs are shown for the NNR (Fig. 3a, c, respectively) and for the model ensemble (Fig. 3b, d, respectively). Note that some of the models are not defined at $700 \mathrm{hPa}$ over topographic features such as Greenland and the Himalayas. Longitudeheight cross sections, area-averaged from $50^{\circ} \mathrm{N}$ to $80^{\circ} \mathrm{N}$, are also shown for the NNR (Fig. 3e) and for the models (Fig. 3f).

At $700 \mathrm{hPa}$ two significant anomalies appear in both the models and the NNR: a ridge over the western part of northern Eurasia and a trough over the Northeast Asia/ (weighted according to the seasonal cycle) from the zonal mean (positive in bold and negative in thin contours) are shown with black contours (zero contour omitted) with a spacing of $100 \mathrm{~m}$

Bering Strait region (Fig. 3a, b). This anomaly dipole, and the high anomaly over north-western Eurasia in particular, has been shown to be a precursor of weak stratospheric vortex regimes (Limpasuvan et al. 2004; Martius et al. 2009; Garfinkel et al. 2010; Orsolini et al. 2010). As seen perhaps most clearly in Fig. 3b, these anomalies enhance the amplitude of the stationary wave field across the Eurasian continent. From Fig. 3f, it is clear that the anomaly dipole pattern exists throughout the troposphere in the models. In the NNR (Fig. 3e), the same pattern is seen, although it is only statistically significant in the lower troposphere. The negative anomalies over southern Europe and Southeast Asia are too far to the south to be included in Fig. 3e. At $100 \mathrm{hPa}$ (Fig. 3c, d) high anomalies are found between the two stationary ridges over Alaska and the Northeast Atlantic. Our interpretation is that these anomalies, together with the low anomaly in the region near the stationary trough over Asia, act to nudge the polar geopotential height field in the lower stratosphere towards a wave-number one pattern.

It is clear from both the horizontal and vertical plots in Fig. 3 that there is a westward baroclinic tilt with height in the geopotential field. This suggests that advection of air masses is a key factor in the three-dimensional atmospheric development during the months before WVMs.

Throughout the troposphere changes to the geopotential height field prior to WVMs in both the NNR and the large multi-model ensemble act to enhance the pre-existing stationary wave field, as suggested by Garfinkel et al. (2010). The similarity of the patterns for both the NNR and model ensemble suggests that to a large extent model behaviour is similar to that in the re-analysis and lends confidence that such an enhancement of the background stationary wave field is an important precursor to stratospheric WVMs. An obvious supplementary question to consider is if the 

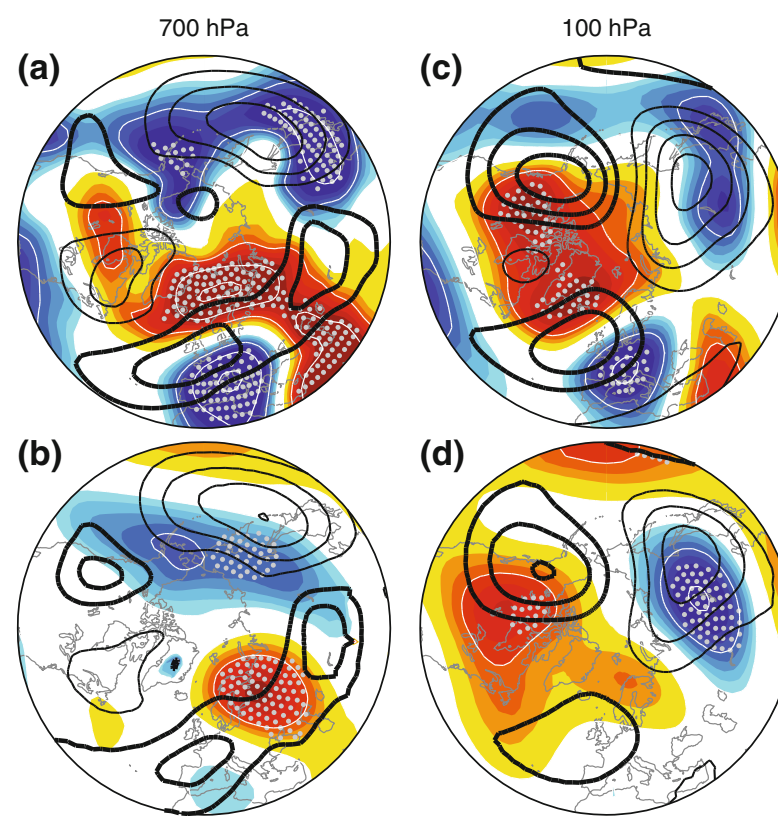

(d)

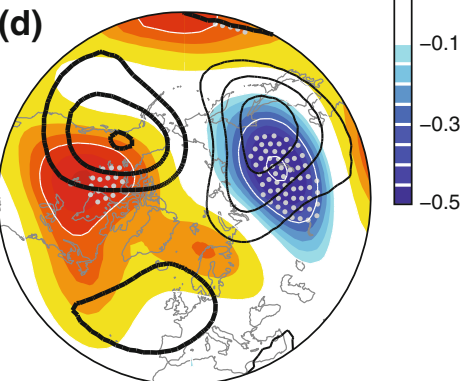

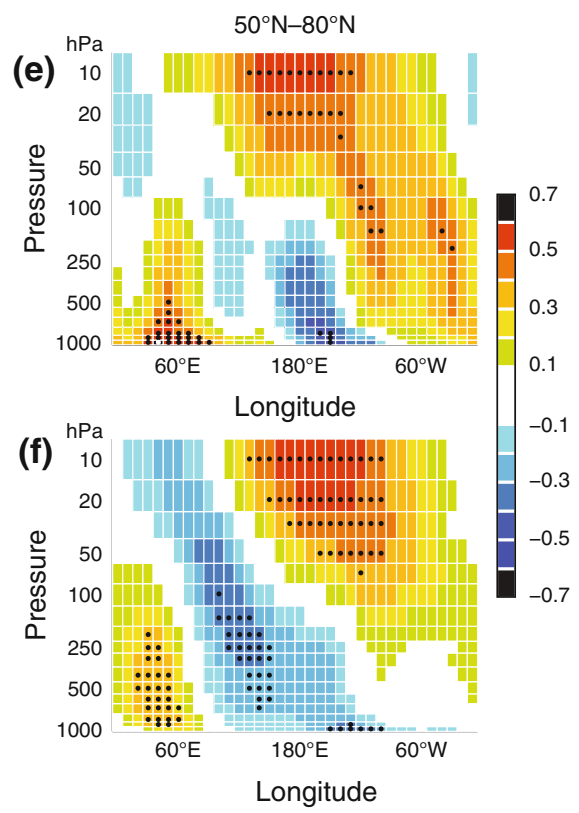

Fig. 3 Geopotential height anomaly precursors of WVMs. a-d Average standardised geopotential height anomalies during the months before WVMs are shown in standard deviation units for the NNR (a, c) and the 13-member model ensemble $(\mathbf{b}, \mathbf{d})$ at $700(\mathbf{a}, \mathbf{b})$ and $100 \mathrm{hPa}(\mathbf{c}, \mathbf{d})$. The model data in $\mathbf{b}$ and $\mathbf{d}$ were interpolated onto the NNR grid. White contours are drawn for each 0.2 standard deviation unit, starting at \pm 0.3 . As in Fig. 2, the black contours show the climatologically weighted stationary wave field, with contour intervals of $50 \mathrm{~m} \mathrm{(a,} \mathrm{b)} \mathrm{and} 70 \mathrm{~m}(\mathbf{c}, \mathbf{d})$. e-f Longitude-height cross

tropospheric origin of the geopotential height anomalies is the same in the models as in the re-analysis data. One diagnostic useful in answering this question is the vertical component of the Plumb flux.

Anomalies in the vertical component of the Plumb flux at $100 \mathrm{hPa}$ prior to WVMs are shown for the NNR in Fig. 4a and for the multi-model ensemble in Fig. 4b. The weighted climatological mean fields are also shown. For the multi-model ensemble, it is clear that the stationary geopotential height anomalies at $100 \mathrm{hPa}$ in Fig. $3 \mathrm{~d}$ are associated with enhanced upward propagating wave activity over East Asia from about $50^{\circ} \mathrm{N}$ to $80^{\circ} \mathrm{N}$ (Fig. 4b). The climatological values show that this is the primary region for upward propagating stationary wave activity, hence an enhancement of the vertical component of the Plumb flux in this region would be consistent with the enhancement of the stationary wave pattern in the troposphere over Eurasia as seen in Fig. 3. For the NNR, a more complex pattern emerges (Fig. 4a). While as in the multi-model ensemble, an overall enhancement of the upward component of the Plumb flux is observed, its horizontal distribution is quite different to that observed in the multi-model ensemble, with a large and significant enhancement of the flux over the western coast of North America. sections of average standardised height anomalies, area-averaged from $50^{\circ} \mathrm{N}$ to $80^{\circ} \mathrm{N}$, during the months before WVMs are shown in standard deviation units for the NNR (e) and the model ensemble (f). The values were interpolated onto a longitude grid with a spacing of $10^{\circ}$. The dots indicate where the anomalies are significant at the 5\% level according to a 1,000-member Monte Carlo test (a, c, e), and where the ensemble mean anomalies are larger than 1.5 times the inter-model standard deviation $(\mathbf{b}, \mathbf{d}, \mathbf{f})$

Figure $4 \mathrm{c}$ and $\mathrm{d}$, where vertical slices of the Plumb flux, area-averaged from $50^{\circ} \mathrm{N}$ to $80^{\circ} \mathrm{N}$, are shown, reveal that this difference between the NNR and multi-model ensemble is not restricted to the $100-\mathrm{hPa}$ level. In the models (Fig. 4d), the largest anomalous Plumb flux anomalies in the stratosphere are confined to the Eurasian continent (west of $180^{\circ} \mathrm{E}$ ). The location of the enhanced fluxes at $100 \mathrm{hPa}$ lends support to the idea that Eurasian snow cover is an important factor in determining the strength of the stratospheric vortex (Cohen et al. 2007), although the magnitude of the wave forcing is lower and less significant in the troposphere than in the stratosphere. The issue of snow cover is discussed in more detail in Sect. 6 below. In the NNR (Fig. 4c), the region over North America is also affected by a surplus of stationary wave fluxes. It is also interesting to note that the Bering Strait region appears to be the most important tropospheric source of surplus stationary wave flux in the NNR, while negative flux anomalies are found to the west of Greenland (Fig. 4c).

\subsection{Strong vortex months}

Previous studies which have compared the structure of strong and weak vortex regimes in the stratosphere in reanalysis datasets (e.g. Limpasuvan et al. 2004, 2005a) have 


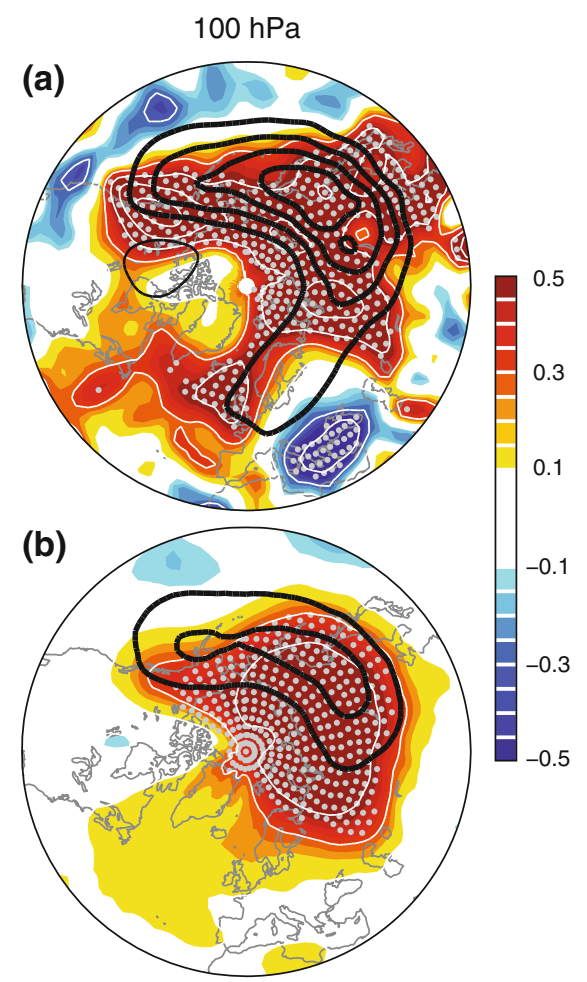

Fig. 4 Vertical plumb flux anomaly precursors of WVMs. a, b Average standardised flux anomalies at $100 \mathrm{hPa}$ during the months before WVMs are shown in standard deviation units for the NNR (a) and the 13-member model ensemble (b). White contours are drawn for each 0.2 standard deviation unit, starting at \pm 0.3 . The black contours show the climatologically weighted average fluxes with a contour interval of $7.5 \times 10^{-3} \mathrm{~m} \mathrm{~s}^{-2}$ (positive in bold and negative in

noted the strong asymmetry between them. To compare the precursors of WVMs and SVMs in the NNR and the CMIP3 models we repeat the analysis of Sect. 4.1 for SVMs. Figure 5 shows average geopotential height anomalies one month before SVMs.

In Fig. 5a-d, the anomaly structure is, to some extent, the inverse of the structure in Fig. 3a-d. At $700 \mathrm{hPa}$, the climatological stationary wave pattern across Eurasia is diminished (Fig. 5a, b), although the magnitudes of the model anomalies are small. At $100 \mathrm{hPa}$, the trough between the two stationary ridges over Alaska and the Northeast Atlantic deepens, while the stationary ridge over East Asia is suppressed (Fig. 5c, d). In both data sets, the negative anomalies dominate. When seen together, Fig. 5a-d suggest that the amplitude of the large-scale stationary wave structure is reduced. The anomalies in the vertical plots, averaged from $50^{\circ} \mathrm{N}$ to $80^{\circ} \mathrm{N}$ (Fig. 5e, f) have opposite signs to the anomalies in Fig. 3e and f, but we note that the only significant anomalies in the models are associated with the upper-level low anomaly between $180^{\circ}$ and $60^{\circ} \mathrm{W}$ (from the Bering Strait to Greenland).

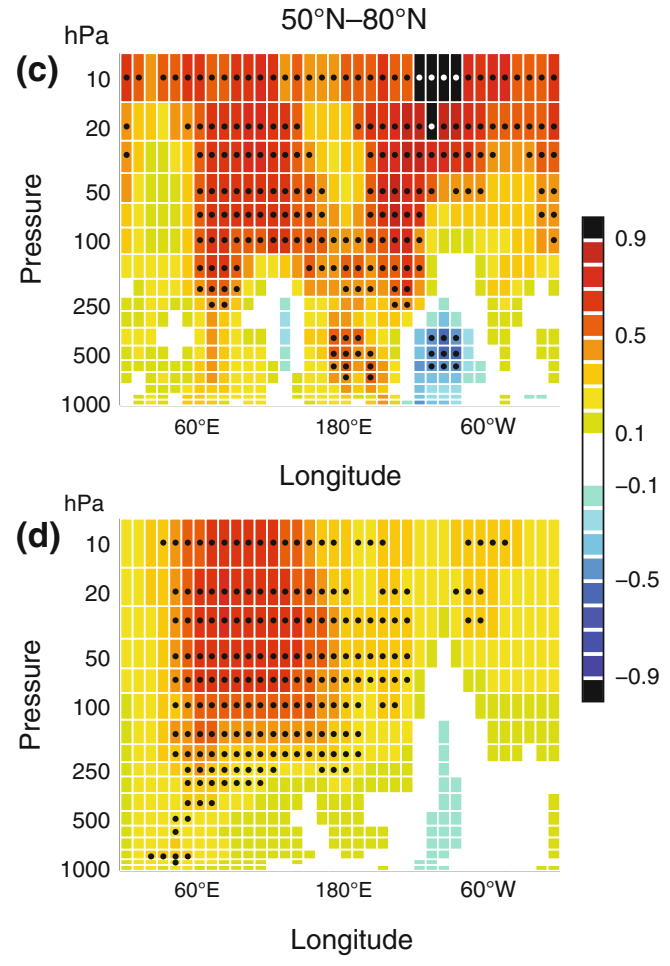

thin contours). The zero contour was omitted. c, d Longitude-height cross sections of average standardised flux anomalies, area-averaged from $50^{\circ} \mathrm{N}$ to $80^{\circ} \mathrm{N}$, during the months before WVMs are shown in standard deviation units for the NNR (c) and the model ensemble (d). The values were interpolated onto a longitude grid with a spacing of $10^{\circ}$. In all the panels, the dots have the same meaning as in Fig. 3

Figure 6 shows the anomalies in the vertical component of the Plumb flux prior to SVMs. There are large differences between the multi-model ensemble and the NNR. During the months before SVMs, there is a strong reduction in vertical Plumb flux over Eurasia in the model ensemble at $100 \mathrm{hPa}$ (Fig. 6b), consistent with the overall reduction in stationary wave amplitudes (Fig. 5b, d). This aligns well with the results of Orsolini et al. (2009; their Fig. 5), who found large negative Plumb flux anomalies over Eurasia prior to cold vortex events. The anomalies in the Plumb flux for the NNR are not confined to eastern Eurasia, and do not have a consistent and significant structure at $100 \mathrm{hPa}$ (Fig. 6a). The vertical plot for the models (Fig. 6d) is essentially the mirror image of Fig. 4d, suggesting that the models display a strong and significant reduction of vertical stationary wave flux over Eurasia above $250 \mathrm{hPa}$ one month before SVMs. In the NNR, the largest negative Plumb flux anomalies are found to the east of the Bering Strait in the lower stratosphere, but the anomalies are not statistically significant anywhere in Fig. 6c. 


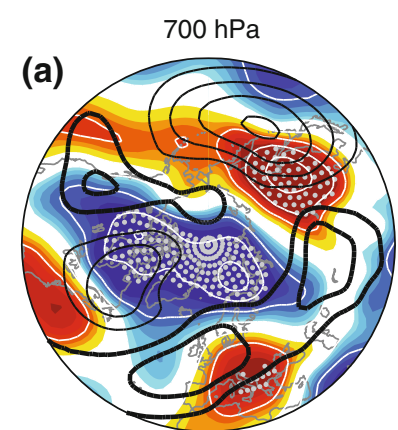

(b)

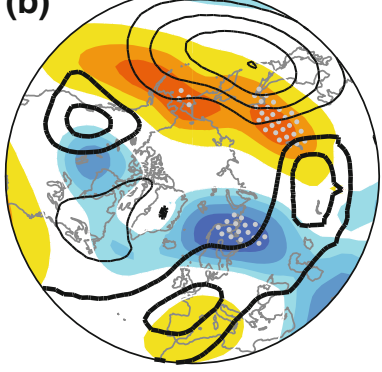

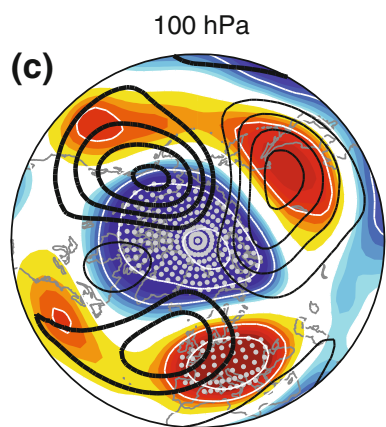

(d)

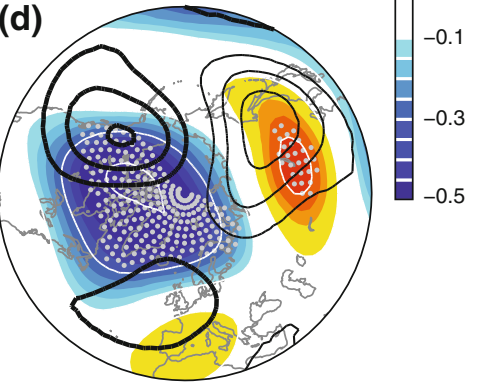

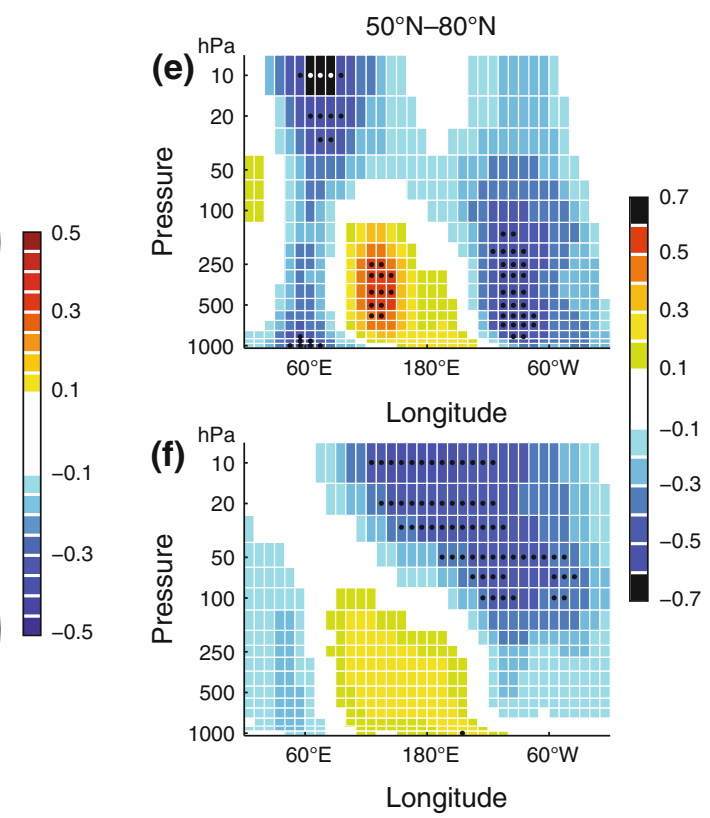

Fig. 5 As Fig. 3, but for SVMs
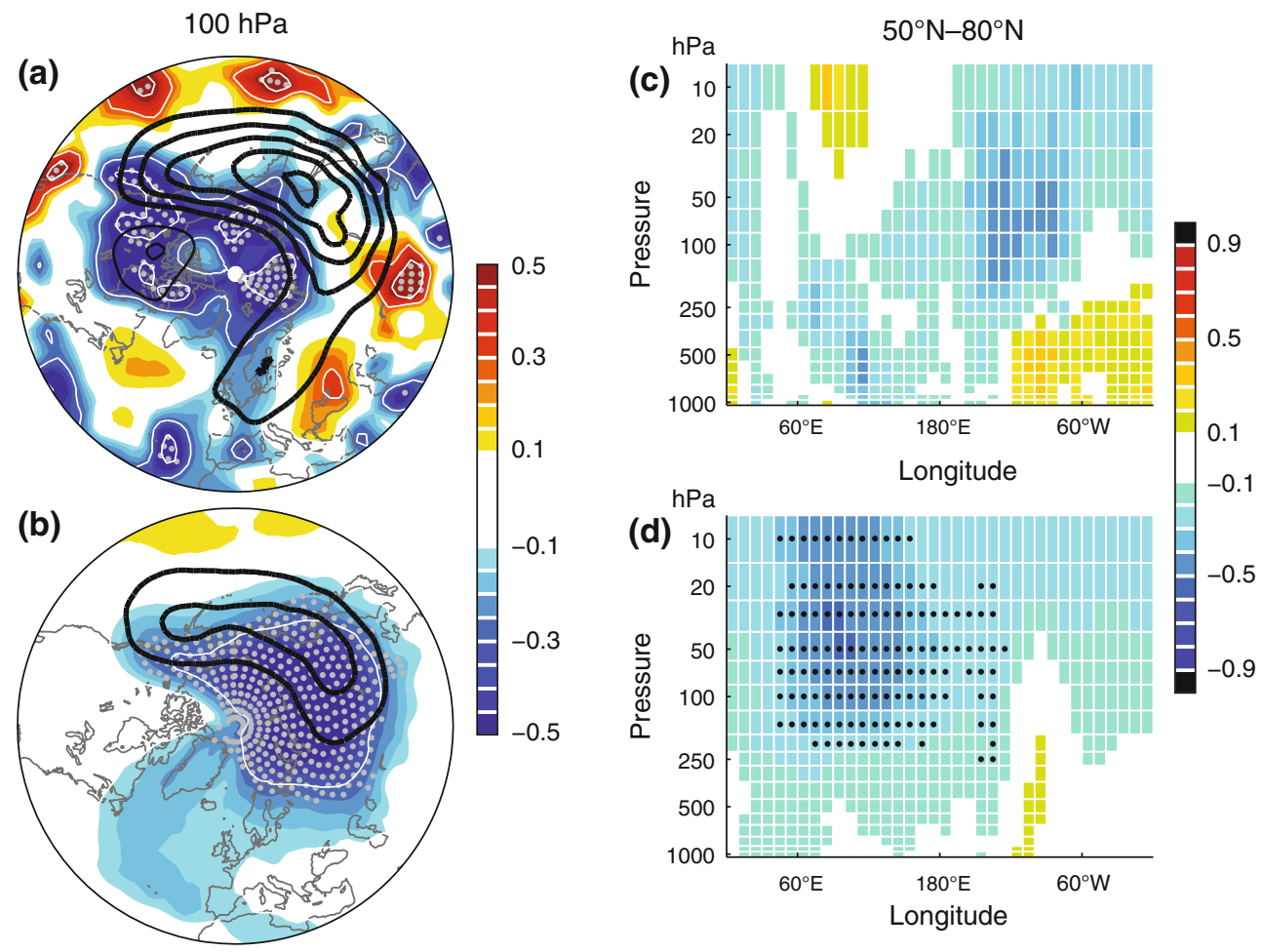

Fig. 6 As Fig. 4, but for SVMs

\section{Understanding inter-model differences}

Although the CMIP3 multi-model ensemble grossly simulates the observed features of lower stratospheric variability and their precursors, the models and the NNR 
wide variation between models might be made by comparing Plumb fluxes throughout the troposphere. A very simple hypothesis to explain differences between the models is that those with low amounts of stratospheric variability lack large variations in stationary wave activity entering the stratosphere from below.

In Sect. 3 we found that the variance of the polar vortex at $50 \mathrm{hPa}$ appeared to be largely proportional to the amplitude of the stationary wave field at the same level. We now investigate whether the long-term variance of the polar vortex (on the monthly time scale) is associated with the stationary waves at other latitudes and vertical levels. To do this, we form a vector with 13 elements from the third column of Table 1, excluding the value for the NNR. This vector, which we call $\sigma_{Z}$, is then correlated in turn with 13-element vectors (one element for each model) for a range of latitudes and pressure levels. The first of these is the long-term standard deviation of the zonally averaged vertical Plumb flux, and the results are shown in Fig. 7a. Note that because some of the models do not provide data for the lower troposphere over topography, only the results from $700 \mathrm{hPa}$ and upwards are shown. The models with large (small) variability in this parameter also have large (small) values of $\sigma_{Z}$ in the polar stratosphere and tropopause region, as indicated by the positive correlations north of $50^{\circ} \mathrm{N}$ and above $200 \mathrm{hPa}$. This suggests that a large stationary wave flux variance in the stratosphere is an important factor in simulating a strongly varying stratospheric polar vortex. The variance of stationary wave fluxes in the polar troposphere appears to be less important. Although it is barely significant, there is an intriguing negative correlation between the stationary wave flux variance in the subtropical troposphere and the variance of the polar vortex. If these are physically meaningful features, models with a limited stationary wave variance at different levels in the subtropics tend to have a large stratospheric polar vortex variance. This apparent link is particularly interesting in the context of the recent interest in the subtropical region as an important source region for waves that can influence stratospheric behaviour. Recent studies (e.g. Garcia and Randel 2008) suggest that observed changes in the Brewer-Dobson circulation over the twentyfirst century (Butchart et al. 2006) might be related to changes in planetary wave generation and propagation from the sub-tropical troposphere.

In Fig. $7 \mathrm{~b}$, the correlations between $\sigma_{Z}$ and the longterm standard deviation of the stationary wave amplitude (the difference between the maximum and minimum values of $[Z]$ along a latitude line), computed from monthly mean data, are shown. As with the variability in zonal-mean Plumb flux, the strongest level of correlation between this quantity and $\sigma_{Z}$ across the models is found in the stratosphere, but now from $100 \mathrm{hPa}$ and upward. Negative correlations, although not significant ones, are found in the polar troposphere and in the subtropical tropopause region.

\section{Discussion}

We have used the NCEP/NCAR re-analysis and long preindustrial control integrations of 13 CMIP3 models to examine the variability of the polar vortex in the stratosphere. The re-analysis only covers about 50 years, while we used 300-year time series from each of the models. We hope that the very large sample size of the model data and the large inter-model differences in terms of both horizontal and vertical resolution have enabled us to extract the most robust precursors of stratospheric polar vortex variability.

By producing composites of both WVMs and SVMs from re-analysis and models we were able to show that these events follow changes to the pre-existing stationary wave pattern in the troposphere. In common with the results of Garfinkel et al. (2010), we find that precursor
Fig. 7 Latitude-height cross sections of the inter-model, month-to-month correlation between the standard deviations of $Z_{\mathrm{PC}}$ anomalies and: a the standard deviations of the zonalmean vertical plumb flux and b the standard deviations of the stationary wave amplitude (the maximum value minus the minimum value along each latitude). The points for which the correlations are significant at the $5 \%$ level are marked with dots

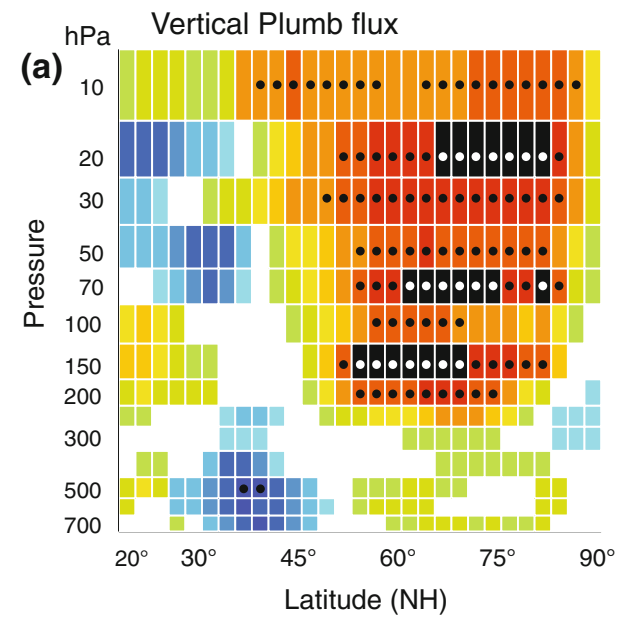

(b)

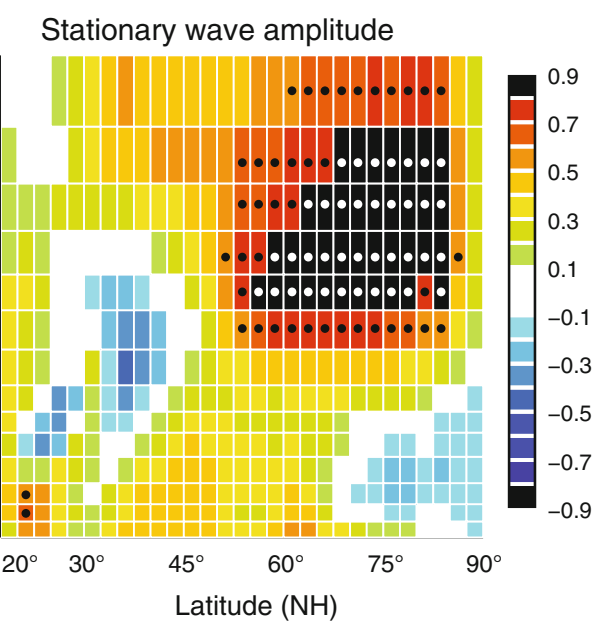


patterns in the troposphere for weak vortex regimes are a ridge over Northeast Europe and a trough over the Bering strait and Northeast Asia. These anomalies are part of a broader baroclinic structure that tends to enhance the preexisting large-scale (predominantly wave-number one) stationary wave pattern (Garfinkel et al. 2010). By comparing these structures in NNR and the ensemble average of the control model simulations we were able to show that these structures are in general well captured by the models. We now discuss the stationary wave forcing found to precede vortex strength anomalies, the discrepancies between the models and the re-analysis, and the implications of our study for forecasting.

\subsection{Stationary wave forcing}

Our analysis of the source of the stationary wave perturbations, using the vertical Plumb flux diagnostic, showed that both the NNR and the models have a surplus of upward stationary wave flux prior to WVMs. This is as expected and consistent with previous studies, such as Liberato et al. (2007), who found a strong lagged correlation between the stratospheric NAM index and wave-number one baroclinic waves. As mentioned earlier, we found that the geopotential height anomaly precursor of WVMs in Fig. 3 acted to enhance the amplitude of the stationary wave pattern. We suggest that this leads to more vigorous meridional advection, which again might lead to amplified meridional heat fluxes, thereby increasing the level of upward propagation of stationary wave flux into the stratosphere. Conversely, the precursors of SVMs might act to decrease the upward wave fluxes. An interesting finding in our study is that the anomalies in the upward wave propagation were primarily confined to the northern part of Eurasia. We are currently investigating the reasons for this and hope to present our results in a future paper.

At first sight, the Eurasian confinement of the stationary wave signal aligns well with the results of Cohen et al. (2007), who proposed that variations in the late autumn Eurasian snow cover explain a certain degree of the wintertime polar vortex variability. Garfinkel et al. (2010) attribute their precursor anomalies both upstream (a high anomaly over eastern Europe) and downstream (a low anomaly over the Northwest Pacific) of northern Eurasia to Eurasian snow cover anomalies. In this study we find no significant stationary wave fluxes in the troposphere over Eurasia, nor do we find significant sea level pressure anomalies prior to WVMs in the Eurasian region for the models (not shown). However, the following analysis lends support to the notion of linkages between Eurasian snow cover and weak vortex regimes in the stratosphere.

Figure 4 showed a clear relationship between positive Plumb flux anomalies at $100 \mathrm{hPa}$ over Eurasia one month before a weakening of the stratospheric polar vortex. We now define a region with corners at $50^{\circ} \mathrm{N}, 80^{\circ} \mathrm{N}, 60^{\circ} \mathrm{E}$ and $150^{\circ} \mathrm{E}$ and compute the area-averaged monthly $100-\mathrm{hPa}$ vertical Plumb flux anomalies with respect to climatology inside that region. The fluxes were computed for the period from November to February. In Fig. 8 composites of geopotential height anomalies during the months for which this index is greater than its overall 90th percentile are shown as horizontal plots at 700 and $100 \mathrm{hPa}$, and as vertical longitude-height plots area-averaged from $50^{\circ} \mathrm{N}$ to $80^{\circ} \mathrm{N}$. As for the WVMs and the SVMs, when two consecutive months satisfied this constraint, only the first of these was used. At $700 \mathrm{hPa}$ (Fig. 8a, b) a distinct wavetrain pattern from the Atlantic to the Pacific is seen. The pattern resembles the one in Fig. $3 a$ and $b$, with a ridge over western Russia and a trough over Northeast Asia in both the NNR and the models. The locations and magnitudes of these anomalies are well matched for both data sets (Fig. 8a, b). At $100 \mathrm{hPa}$, an anomaly dipole consisting of a high over Alaska and a low over Northeast Asia is found (Fig. 8c, d). The location of this dipole is quite similar to the dipole pattern seen in Fig. $3 \mathrm{c}$ and $d$. The vertical plots in Fig. 8e and f show that the tropospheric Eurasian anomaly dipole extends up to the tropopause in both the models and the NNR.

There is a good indication that the patterns in Fig. 8 are consistent with and similar to those associated with snow cover when the horizontal plots are compared to Fig. 7 in Orsolini and Kvamstø (2009), which shows the December geopotential height anomalies after above-normal snow cover over Eurasia during the autumn-winter transition (October-December). Their plot for the 250-hPa level shows a Eurasian wave train in excellent agreement with our Fig. 8. The modelling study of Fletcher et al. (2009) also generates an Atlantic-Pacific wave-train as a response to Eurasian snow cover perturbations. Because a recent study (Hardiman et al. 2008) indicated that the CMIP3 climate models are unable to reproduce the observed effects of Eurasian snow cover on the wintertime climate in the $\mathrm{NH}$, we have not tried to associate enhanced Eurasian stationary wave fluxes to snow cover in the models. Although snow cover variations are probably an important factor, much work remains to explain exactly how the large vertical flux anomalies over Eurasia in the models come about. Here we simply note the importance of this region in generating precursors to stratospheric variability.

\subsection{Discrepancies between models and re-analysis}

In spite of the many similarities between the precursor patterns in the NNR and the models, there are also distinct differences between their stationary wave forcing. In particular, the models do not exhibit the large changes in the 

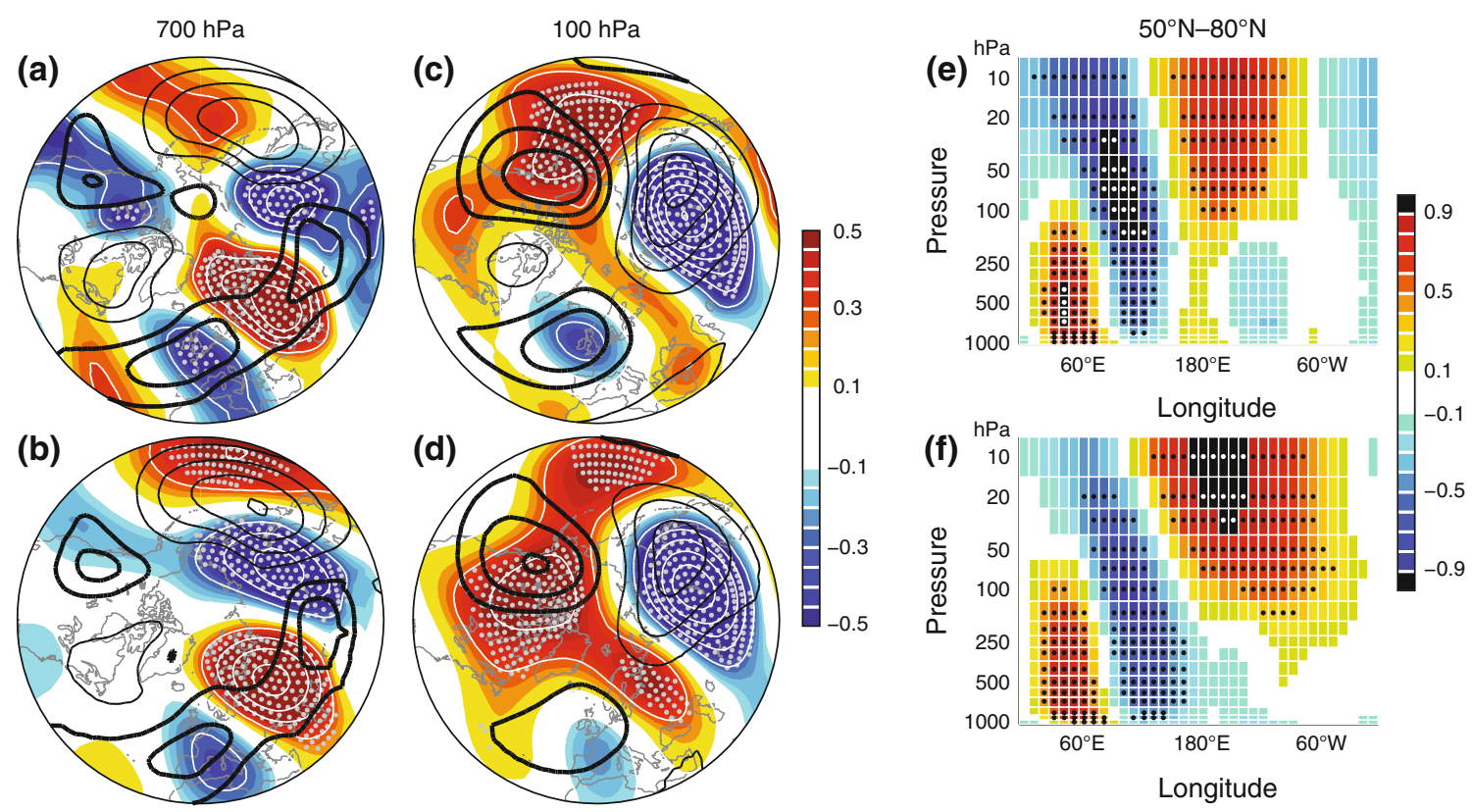

Fig. 8 As Fig. 3, but for the November to February months for which the northern Eurasian (area-averaged inside a region with corners at $50^{\circ} \mathrm{N}, 80^{\circ} \mathrm{N}, 60^{\circ} \mathrm{E}$ and $150^{\circ} \mathrm{E}$ ) vertical Plumb flux anomalies at

stationary wave amplitude over western North America seen in the NNR. The distinction between models and the NNR is even greater when the source of anomalous stationary wave precursors to SVMs is considered. In the models, the Plumb flux anomalies for WVMs and SVMs are almost symmetric between WVMs and SVMs, while in the NNR, the Plumb flux anomalies prior to SVMs are concentrated over western North America and the Arctic. When averaged from $50^{\circ} \mathrm{N}$ to $80^{\circ} \mathrm{N}$, these structures were not significant at any level or latitude for the NNR. This raises an important question: Why are extreme vortex events in the CMIP3 models not linked to a stationary wave source over western North America?

Garfinkel et al. (2010) and others connect stationary wave variability in the North Pacific and western North America with ENSO variability in the North Pacific. Therefore, the large discrepancy in the representation of ENSO variability between the CMIP3 models (Lloyd et al. 2009) is an obvious candidate for the missing source of stratospheric variability in this region. It is worth noting, however, that the climatological stationary wave structure in the same region in the CMIP3 models is well correlated with that found in re-analysis products (Brandefelt and Kornich 2008). In addition, as noted by Ting et al. (1996), a great deal of the variability in stationary wave structure and amplitude is related to the structure of the tropospheric zonally averaged zonal wind, independent of tropical SST forcing. It is also important to take care in the comparison of stratospheric WVMs and SVMs, which are unlikely to
$100 \mathrm{hPa}$ are larger than their 90th percentile. Note that the colour scheme for the panels in $\mathbf{e}$ and $\mathbf{f}$ is different to the one for the corresponding panels in Fig. 3

be symmetrical. As noted by Polvani and Waugh (2004): «In some sense only the weak vortex ESEs [extreme stratospheric events] are true "events," insofar as something has in fact happened (notably, a much larger than average upward wave propagation followed by wave breaking, typical of a sudden warming).»

In addition to considering the performance of the multimodel ensemble we also compared stratospheric variability and stationary wave behaviour across the ensemble. Both in terms of the variability of stationary wave amplitude and variability of the Plumb flux, there was a strong correlation with stratospheric vortex variability. Models that have larger (smaller) amounts of stationary wave variability in the upper troposphere also tend to have stronger (weaker) vortex variability in the stratosphere. The potential consequences of missing sources of stationary wave variability in climate models for prediction of stratospheric variability are large, particularly in the context of the role of the stratosphere in winter season predictability in Europe and Asia. Understanding of the rich range of dynamical behaviour exhibited by stratosphere-resolving climate models is at an early stage. It is clear, however, that models with similar underlying climatological stratospheric jets can have very different amounts of stratospheric variability and produce stratospheric variability with a different structure and seasonal cycle (Charlton et al. 2007). Furthermore, it has not been possible to date to understand these differences in stratospheric variability in terms of basic parameters of the model design such as the position 


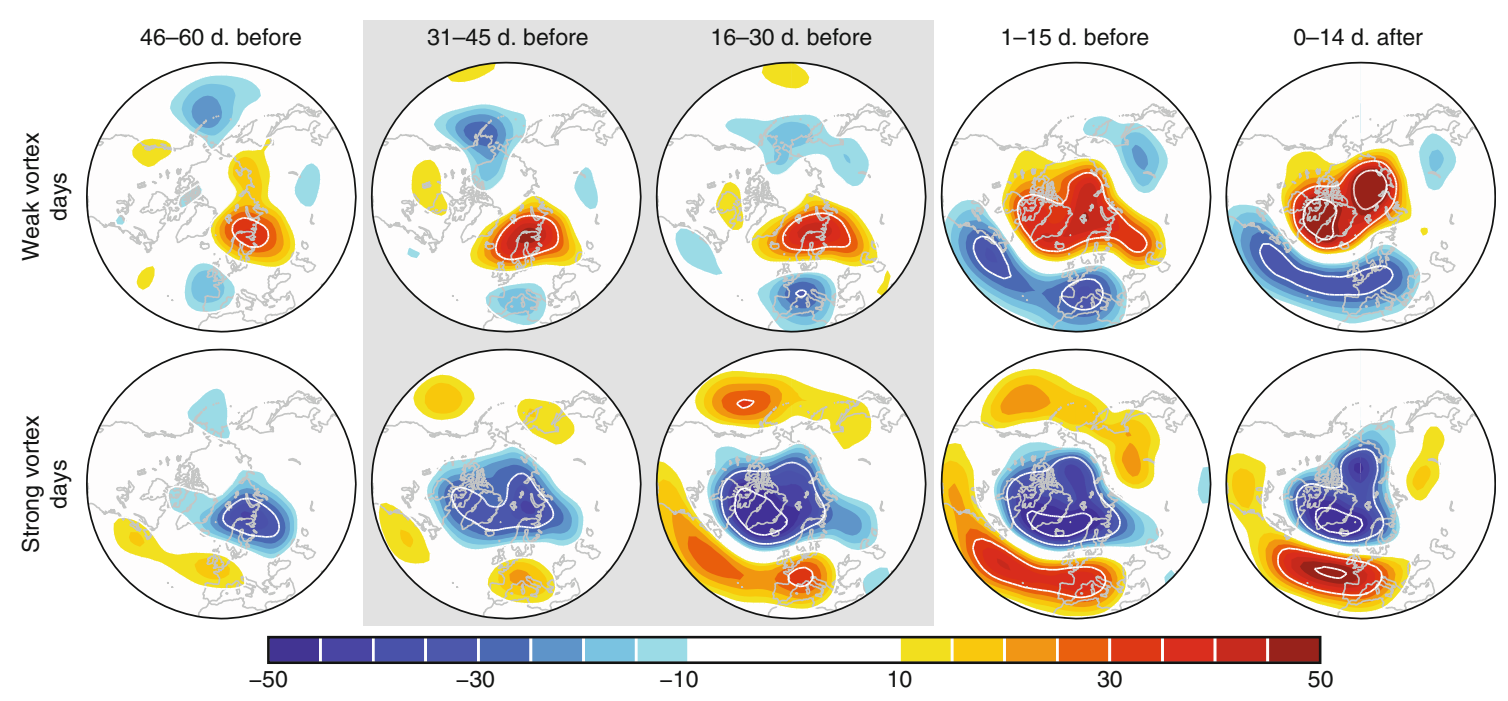

Fig. 9 Geopotential height anomaly precursors of WVDs and SVDs. In the top (bottom) row the average 700-hPa geopotential height anomalies during the specified time intervals relative to WVDs (SVDs) are shown. The unit is metres and white contours are shown

of the model top or its vertical resolution. It may therefore be more useful to attempt to understand these differences in terms of their tropospheric sources of planetary wave activity such as ENSO and Eurasian snow cover.

\subsection{Implications for forecasting}

Perhaps the most important motivation for studies such as this one is to improve the prospects of seasonal forecasting. It is known that anomalies in the strength and location of the stratospheric vortex are linked to fairly well understood tropospheric weather anomalies in the subsequent 2 months or so. If reliable precursors of stratospheric vortex anomalies can be identified, there is a potential for improving longrange weather forecasts. We have identified robust tropospheric precursors, but as only monthly mean data were used the temporal resolution of our results is coarse. In order to assess the life cycle of the precursor pattern on a higher temporal resolution, we now use daily mean data from the NNR to compute daily values of 50-hPa polar cap averaged geopotential height anomalies as described in Kolstad et al. (2010) for the 52 winters (DJFM) from December 1958 to March 2010. We define weak vortex days (WVDs) as the days for which the height anomalies are greater than their overall 90th percentile and strong vortex days (SVDs) are the days when the anomalies are less than their 10th percentile.

In the top row of Fig. 9 the average 700-hPa geopotential height anomalies during the specified time periods relative to the WVDs are shown. Note that the anomalies are given in metres and not standard deviation units as before. In the interval from 16 to 45 days before the WVDs, which corresponds to the month before WVMs in for each $20 \mathrm{~m}$, starting at $\pm 30 \mathrm{~m}$. The time intervals that correspond to one month before WVMs and SVMs when using monthly mean data are drawn against a gray background

the monthly mean data, the precursor of WVDs is dominated by a high anomaly over western Eurasia, in agreement with Fig. 3a. The low anomalies over Europe and Northeast Asia are less distinct in Fig. 9 than in Fig. 3a. As the sample size of the data used to produce Fig. 9 is larger than the sample size for Fig. $3 \mathrm{a}$, this suggests that the western Eurasia high is the most robust tropospheric precursor of weak vortex events. This conjecture is backed up by the domination of the western Eurasia high precursor for the models in Fig. 3b, which was also computed from a very large data sample. The western Eurasia high is also present in the period from 46 to 60 days before the WVDs (Fig. 9) - another indication of robustness in this precursor. In the period from 15 days before to 14 days after the WVDs (Fig. 9) the high anomaly moves westwards and a negative NAO pattern gradually develops as expected.

The height anomalies relative to SVDs are shown in the bottom panel of Fig. 9. During the 46-60 days before the SVDs a negative height anomaly with slightly larger amplitude than the positive height anomaly in the same interval relative to the WVDs is found over western Eurasia. By 16-30 days before the SVDs, the negative anomaly has moved westwards and the overall anomaly pattern projects on the positive phase of the NAO. This means that the gradual transition to an NAO-like pattern occurs earlier in the life cycle for SVDs than for WVDs. It is also interesting to note that the positive height anomaly precursor of SVMs over Northeast Asia seen in Fig. 5a is absent in Fig. 9.

To sum up, the leftmost panels in Fig. 9 indicate that there is a potential for prediction of anomalous vortex events on the intra-seasonal time scale. Similar robust precursor 
patterns to stratospheric vortex variability events have been identified by other authors (e.g. Limpasuvan et al. 2004, 2005a) and the importance of the Siberian high has also been discussed (Cohen et al. 2001). If the presence of tropospheric precursors up to 60 days before the onset of such events can be translated into predictive skill, it would have positive implications for long-range and seasonal forecasting of wintertime weather in large regions of the NH. An important part of this process is the continued understanding and assessment of coupling between the stratosphere and troposphere in state-of-the-art general circulation models.

\section{Conclusions}

The most robust precursor of stratospheric polar vortex events consisted of a geopotential height anomaly dipole across the northern part of the Eurasian continent. Prior to weak (strong) vortex regimes, this precursor was found to be associated with increased (decreased) upward propagation of stationary wave fluxes over Eurasia. Similar patterns have been found to be associated with anomalies in Eurasian snow cover.

We found a large degree of agreement between reanalysis data and pre-industrial control runs from an ensemble of 13 coupled climate models, even though the models covered a wide range of stratospheric resolutions and model lid heights. The models that had a large (small) stationary wave amplitude in the stratosphere and strong (weak) stratospheric stationary wave flux variability, both in the region around $60^{\circ} \mathrm{N}$, also had strong (weak) stratospheric polar vortex variability.

Acknowledgments We thank Yvan Orsolini, Tarjei Breiteig and three reviewers for comments and discussions that led to an improved paper. We also acknowledge the modelling groups, the Program for Climate Model Diagnosis and Intercomparison (PCMDI) and the WCRP's Working Group on Coupled Modelling (WGCM) for making available the CMIP3 multi-model dataset, as well as NOAA/ OAR/ESRL PSD for providing the NCEP/NCAR re-analysis data. Erik Kolstad's work was funded by the Norwegian Research Council through its International Polar Year programme and the project IPYTHORPEX (grant number 175992/S30). This is publication no. A301 from the Bjerknes Centre for Climate Research.

Open Access This article is distributed under the terms of the Creative Commons Attribution Noncommercial License which permits any noncommercial use, distribution, and reproduction in any medium, provided the original author(s) and source are credited.

\section{References}

Ambaum MHP, Hoskins BJ (2002) The NAO troposphere-stratosphere connection. J Clim 15:1969-1978
Baldwin MP, Dunkerton TJ (1999) Propagation of the Arctic oscillation from the stratosphere to the troposphere. J Geophys Res 104:30937-30946

Baldwin MP, Dunkerton TJ (2001) Stratospheric harbingers of anomalous weather regimes. Science 294:581-584

Baldwin MP, Thompson DWJ (2009) A critical comparison of stratosphere-troposphere coupling indices. Q J R Meteorol Soc 135:1661-1672

Baldwin MP, Stephenson DB, Thompson DWJ, Dunkerton TJ, Charlton AJ, O'Neill A (2003) Stratospheric memory and skill of extended-range weather forecasts. Science 301:636-640

Bell CJ, Gray LJ, Charlton-Perez AJ, Joshi MM, Scaife AA (2009) Stratospheric communication of El Niño teleconnections to European winter. J Clim 22:4083-4096

Brandefelt J, Kornich H (2008) Northern hemisphere stationary waves in future climate projections. J Clim 21:6341-6353

Butchart N, Scaife AA, Bourqui M, de Grandpre J, Hare SHE, Kettleborough J, Langematz U, Manzini E, Sassi F, Shibata K, Shindell D, Sigmond M (2006) Simulations of anthropogenic change in the strength of the Brewer-Dobson circulation. Clim Dyn 27:727-741

Cagnazzo C, Manzini E (2009) Impact of the stratosphere on the winter tropospheric teleconnections between ENSO and the North Atlantic and European region. J Clim 22:1223-1238. doi: 10.1175/2008JCLI2549.1

Castanheira JM, Liberato MLR, de la Torre L, Graf HF, DaCamara CC (2009) Baroclinic rossby wave forcing and barotropic rossby wave response to stratospheric vortex variability. J Atmos Sci 66:902-914

Charlton AJ, O'Neill A, Stephenson DB, Lahoz WA, Baldwin MP (2003) Can knowledge of the state of the stratosphere be used to improve statistical forecasts of the troposphere? Q J R Meteorol Soc 129:3205-3224. doi:10.1256/qj.02.232

Charlton AJ, O'Neill A, Lahoz WA, Massacand AC (2004) Sensitivity of tropospheric forecasts to stratospheric initial conditions. Q J R Meteorol Soc 130:1771-1792

Charlton AJ, Polvani LM, Perlwitz J, Sassi F, Manzini E, Shibata K, Pawson S, Nielsen JE, Rind D (2007) A new look at stratospheric sudden warmings. Part II: evaluation of numerical model simulations. J Clim 20:470-488

Cohen J, Entekhabi D (1999) Eurasian snow cover variability and northern hemisphere climate predictability. Geophys Res Lett 26:345-348. doi:10.1029/1998g1900321

Cohen J, Fletcher C (2007) Improved Skill of northern hemisphere winter surface temperature predictions based on land-atmosphere fall anomalies. J Clim 20:4118-4132. doi:10.1175/JCLI4241.1

Cohen J, Saito K, Entekhabi D (2001) The role of the siberian high in northern hemisphere climate variability. Geophys Res Lett 28:299-302. doi:10.1029/2000g1011927

Cohen J, Entekhabi D, Saito K, Gong G, Salstein D (2005) The life cycle of the Northern Hemisphere sudden stratospheric warmings - comment. J Clim 18:2775-2777

Cohen J, Barlow M, Kushner PJ, Saito K (2007) StratosphereTroposphere coupling and links with Eurasian land surface variability. J Clim 20:5335-5343

Cordero EC, Forster PMdF (2006) Stratospheric variability and trends in models used for the IPCC AR4. Atmos Chem Phys 6:5369-5380

Douville H (2009) Stratospheric polar vortex influence on northern hemisphere winter climate variability. Geophys Res Lett 36 . doi: 10.1029/2009g1039334

Fletcher CG, Kushner PJ, Cohen J (2007) Stratospheric control of the extratropical circulation response to surface forcing. Geophys Res Lett 34:L21802. doi:10.1029/2007g1031626

Fletcher CG, Hardiman SC, Kushner PJ, Cohen J (2009) The dynamical response to snow cover perturbations in a large 
ensemble of atmospheric GCM integrations. J Clim 22: $1208-1222$

Garcia RR, Randel WJ (2008) Acceleration of the Brewer-Dobson circulation due to increases in greenhouse gases. J Atmos Sci 65:2731-2739

Garfinkel CI, Hartmann DL, Sassi F (2010) Tropospheric precursors of anomalous northern hemisphere stratospheric polar vortices. J Clim 23:3282-3299. doi:10.1175/2010JCLI3010.1

Gerber EP, Polvani LM (2009) Stratosphere-Troposphere coupling in a relatively simple AGCM: the importance of stratospheric variability. J Clim 22:1920-1933

Hardiman SC, Kushner PJ, Cohen J (2008) Investigating the ability of general circulation models to capture the effects of Eurasian snow cover on winter climate. J Geophys Res 113. doi: $10.1029 / 2008 \mathrm{jd} 010623$

Ineson S, Scaife AA (2009) The role of the stratosphere in the European climate response to El Nino. Nat Geosci 2:32-36

Kalnay E, Kanamitsu M, Kistler R, Collins W, Deaven D, Gandin L, Iredell M, Saha S, White G, Woollen J, Zhu Y, Chelliah M, Ebisuzaki W, Higgins W, Janowiak J, Mo KC, Ropelewski C, Wang J, Leetmaa A, Reynolds R, Jenne R, Joseph D (1996) The NCEP/NCAR 40-year reanalysis project. Bull Am Meteorol Soc 77:437-471

Karoly DJ, Plumb RA, Ting M (1989) Examples of the horizontal propagation of quasi-stationary waves. J Atmos Sci 46: 2802-2811

Kolstad EW, Breiteig T, Scaife AA (2010) The association between stratospheric weak polar vortex events and cold air outbreaks in the Northern Hemisphere. Q J R Meteorol Soc 136:886-893. doi: 10.1002/qj.620

Liberato MLR, Castanheira JM, de la Torre L, DaCamara CC, Gimeno L (2007) Wave energy associated with the variability of the stratospheric polar vortex. J Atmos Sci 64:2683-2694

Limpasuvan V, Thompson DWJ, Hartmann DL (2004) The life cycle of the northern hemisphere sudden stratospheric warmings. J Clim 17:2584-2596

Limpasuvan V, Hartmann DL, Thompson DWJ, Jeev K, Yung YL (2005a) Stratosphere-troposphere evolution during polar vortex intensification. J Geophys Res 110:D24101. doi:10.1029/ 2005jd006302

Limpasuvan V, Thompson DWJ, Hartmann DL (2005b) The life cycle of the Northern Hemisphere sudden stratospheric warmings-reply. J Clim 18:2778-2780

Lloyd J, Guilyardi E, Weller H, Slingo J (2009) The role of atmosphere feedbacks during ENSO in the CMIP3 models. Atmos Sci Lett 10:170-176

Martius O, Polvani LM, Davies HC (2009) Blocking precursors to stratospheric sudden warming events. Geophys Res Lett 36:L14806. doi:10.1029/2009g1038776

Maycock A, Keeley S, Charlton-Perez A, Doblas-Reyes F (2010) Stratospheric circulation in seasonal forecasting models: implications for seasonal prediction. Clim Dyn (in press). doi: 10.1007/s00382-009-0665-x

Meehl GA, Covey C, Delworth T, Latif M, McAvaney B, Mitchell JFB, Stouffer RJ, Taylor KE (2007) THE WCRP CMIP3 Multimodel Dataset: a new Era in climate change research. Bull Am Meteorol Soc 88:1383-1394

Orsolini YJ, Kvamstø NG (2009) Role of Eurasian snow cover in wintertime circulation: decadal simulations forced with satellite observations. J Geophys Res 114:D19108. doi:10.1029/ 2009jd012253

Orsolini YJ, Karpechko AY, Nikulin G (2009) Variability of the Northern Hemisphere polar stratospheric cloud potential: the role of North Pacific disturbances. Q J R Meteorol Soc 135: 1020-1029

Orsolini Y, Kindem I, Kvamstø NG (2010) On the potential impact of the stratosphere upon seasonal dynamical hindcasts of the North Atlantic Oscillation: a pilot study. Clim Dyn (in press). doi: 10.1007/s00382-009-0705-6

Otterå OH, Bentsen M, Bethke I, Kvamstø NG (2009) Simulated preindustrial climate in Bergen climate model (version 2): model description and large-scale circulation features. Geosci Model Dev 2:197-212

Plumb RA (1985) On the three-dimensional propagation of stationary waves. J Atmos Sci 42:217-229

Polvani LM, Waugh DW (2004) Upward wave activity flux as a precursor to extreme stratospheric events and subsequent anomalous surface weather regimes. J Clim 17:3548-3554

Randel WJ, Shine KP, Austin J, Barnett J, Claud C, Gillett NP, Keckhut P, Langematz U, Lin R, Long C, Mears C, Miller A, Nash J, Seidel DJ, Thompson DWJ, Wu F, Yoden S (2009) An update of observed stratospheric temperature trends. J Geophys Res 114. doi:10.1029/2008jd010421

Reichler T, Kushner PJ, Polvani LM (2005) The coupled stratospheretroposphere response to impulsive forcing from the troposphere. J Atmos Sci 62:3337-3352

Saito K, Cohen J, Entekhabi D (2001) Evolution of atmospheric response to early-season Eurasian snow cover anomalies. Mon Weather Rev 129:2746-2760

Scaife AA, Knight JR, Vallis GK, Folland CK (2005) A stratospheric influence on the winter NAO and North Atlantic surface climate. Geophys Res Lett 32:L18715

Smith KL, Fletcher CG, Kushner PJ (2010) The role of linear interference in the Annular Mode response to extratropical surface forcing. J Clim (in press). doi:10.1175/2010JCLI3606.1

Stan C, Straus DM (2009) Stratospheric predictability and sudden stratospheric warming events. J Geophys Res 114. doi: 10.1029/2008jd011277

Thompson DWJ, Baldwin MP, Wallace JM (2002) Stratospheric connection to Northern Hemisphere wintertime weather: implications for prediction. J Clim 15:1421-1428

Ting MF, Hoerling MP, Xu TY, Kumar A (1996) Northern hemisphere teleconnection patterns during extreme phases of the zonal-mean circulation. J Clim 9:2614-2633

Uppala SM, Kållberg PW, Simmons AJ, Andrae U, Bechtold VD, Fiorino M, Gibson JK, Haseler J, Hernandez A, Kelly GA, Li X, Onogi K, Saarinen S, Sokka N, Allan RP, Andersson E, Arpe K, Balmaseda MA, Beljaars ACM, Van De Berg L, Bidlot J, Bormann N, Caires S, Chevallier F, Dethof A, Dragosavac M, Fisher M, Fuentes M, Hagemann S, Holm E, Hoskins BJ, Isaksen L, Janssen PAEM, Jenne R, McNally AP, Mahfouf JF, Morcrette JJ, Rayner NA, Saunders RW, Simon P, Sterl A, Trenberth KE, Untch A, Vasiljevic D, Viterbo P, Woollen J (2005) The ERA-40 re-analysis. Quart J Roy Meteor Soc 131:2961-3012

Wittman MAH, Polvani LM, Scott RK, Charlton AJ (2004) Stratospheric influence on baroclinic lifecycles and its connection to the Arctic oscillation. Geophys Res Lett 31. doi:10.1029/ 2004 g1020503 